\title{
Myongenic Markers in the Evaluation of Embryonal Botryoid Rhabdomyosarcoma of the Female Genital Tract
}

\author{
Wolfram F. J. Riedlinger, Harry P. W. Kozakewich, and Sara O. Vargas \\ Department of Pathology, Children's Hospital Boston, 300 Longwood Avenue, Boston, MA 02115, USA
}

(Pediatric and Developmental Pathology 8, 355-361, 2005, DOI: 10.1007/s10024-005-3177-7, and Pediatric and Developmental Pathology 8, 427-434, 2005, DOI: 10.1007/s10024-005-0006-y)

This article was erroneously printed in duplicate, once in Volume 8, Number 3, May/June 2005, pages 355-361, and once in Volume 8, Number 4, July/August 2005, pages 427-434. We apologize for this mistake. The correct and valid reference is "Riedlinger WFJ, Kozakewich HPW, Vargas SO. Myogenic markers in the evaluation of embryonal botryoid rhabdomyosarcoma of the female genital tract. Pediatr Dev Pathol 2005;8:355-361, DOI: 10.1007/s10024-005-3177-7." 